\title{
Scapular Malalignment in Patients with Stroke: A Narrative Review
}

\section{Eram N Kazi *1, Suvarna S Ganvir 2.}

${ }^{*}$ Post Graduate Student, D.V.V.P. F'S College of Physiotherapy, Ahmednagar, Maharashtra, India.

${ }^{2}$ Head of the Department, D.V.V.P. F'S College of Physiotherapy, Ahmednagar, Maharashtra, India.

\section{ABSTRACT}

Background: Scapular Malalignment leads to functional incapacity in stroke patients. This malalignment hampers the functional mobility and stability of shoulder joint in stroke patients due to which there is reduced range of motion and hampers activities of daily living in stroke patients. So, to investigate the extent of scapular malalignment in patients with acute, chronic and sub-acute stroke.

Methods: Four databases (PubMed, Google Scholar, Cochrane, Science Direct) were searched to identify eligible studies using the keywords Scapular Malalignment and Stroke. Only observational studies published in last 10 years (2010-2020) were included in this review.

Results: Eight Studies, included in the review were conducted on patients with acute, sub-acute and chronic stage. The results showed that there is more of inferior angle tilting seen in patients with stroke and it increases with spasticity and alters functional mobility in patients with stroke.

Discussion: All studies were consistent in using the appropriate tools for measurement of scapular malalignment. Literature showed scapular malalignment affects scapular balance angle, functional mobility of hand and range of motion in patients with acute, sub-acute and chronic stroke. Most of the literature includes patients with sub-acute and chronic stroke. There was no conflict of evidence observed among all articles.

Conclusion: There is influence of Scapular malalignment on spasticity, duration of stroke, upper limb mobility, and range of motion in stroke patients. Scapular Malalignment is observed in acute, sub-acute and chronic rotation and there is more of inferior angle tilting and rotation of scapula observed.

KEY WORDS: Scapular Malalignment, stroke.

Address for correspondence: Dr. Eram N Kazi, D.V.V.P. F'S College of Physiotherapy, Ahmednagar, Maharashtra, India. E-Mail: emuukazi97@gmail.com

Access this Article online

\section{Quick Response code}

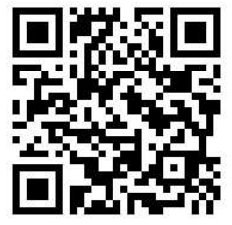

DOI: $10.16965 /$ ijpr.2021.192
Journal Information

International Journal of Physiotherapy and Research ISSN (E) 2321-1822 | ISSN (P) 2321-8975 https://www.ijmhr.org/ijpr.html

DOI-Prefix: https://dx.doi.org/10.16965/ijpr

\section{Article Information}

Received: 26 Aug 2021

Peer Review: 28 Aug 2021

Revised: None
Accepted: 05 Oct 2021

Published (O): 11 Dec 2021

Published (P): 11 Dec 2021

\section{INTRODUCTION}

Stroke is the sudden loss of neurological function caused by an interruption of blood flow to the brain [1], Stroke is an acute cerebrovascular disease caused by haemorrhage or infarction induced cerebral blood supply interruption [2].

According to WHO Study among 12 countries, Stroke has been reported as a world-wide health problem; with incidence ranging from 0.2 to 2.5 per thousand per year. In today's time in India there have been only a few communities based studies for either prevalence or incidence of stroke with prevalence rate of $334 / 100,000$ [3]. The clinical manifestation and effects of stroke depends on the extent of lesion and part of brain damage [2].

Stroke patients have weakness, poor voluntary 
control, imbalance and alignment which affect the ability of an affected arm which further change scapular orientation due to weakness of scapular muscles. This weakness increases motor impairment in upper limb [4].

Scapular malalignment in stroke: Incapacity of upper limb has been considered as a major issue in Stroke Patients [5]. Alterations in scapular biomechanics could lead to instabilities of shoulder joint which can cause shoulder pain or subluxation in shoulder joint [6].

There are studies done to see the glenohumeral elevation in patients with subacromial impingement syndrome, scapular winging is increased (decreased posterior tilt) and lateral rotation (also referred to as upward rotation i.e., angulus inferior of the scapula moves outwards and upwards) is decreased [7].

Cause of scapular malalignment in stroke: Following Stroke, there is a flaccidity with no voluntary control, which is later followed by spasticity which causes alterations in shoulder joint which later affects the scapulothoracic joint asymmetry which is also scapular malalignment or dyskinesia. There are many neurological components such as joint sense and motor functions which affect the scapular dyskinesis [8]. In flaccid stage due to hypotonia of the scapular muscles causes change in glenoid fossa angle leading to scapular depression and protraction. In spastic stage, the flexor tone predominates causing retraction and depression with adduction at shoulder joint. Changes in the position and movement of scapula is termed as Scapular dyskinesis or malalignment which is the loss of ordinary movement of scapula $[9,10]$. Studies shows that disrupt timings and activation of scapular muscles and rotator cuff muscles further alters the range of motion in Stroke patients. Studies shows that Gravity plays a role by pulling the scapula in downward rotation and also patient's posture leads to scapular malalignment as the patient's tend to sway on the unaffected side while maintaining posture, this is due to loss of equilibrium, spasticity, weakness and righting reactions therefore trunk often assumes asymmetrical posture which later leads to scoliosis. There is also tightening of Sternocleidomastoid muscles altering the line of pull $[2,7]$. Due to Scapular malalignment, there is shoulder pain and shoulder dysfunction observed in stroke patients. Scapular malalignment also affects performance of upper limb [11].

Various outcomes used in studies to measure scapular malalignment: In this study there are various methods used for assessment of scapular alignment such as Lennie's test, Protractor, palpation Meter, Scapular Balance Angle, Lateral scapular Slide Test, Digital Inclinometer, Acromial distance Test, electromagnetic sensor. Instruments such as Protractor, goniometer, palpation meter, Scapular Balance Angle and Inclinometer measures the scapular malalignment in degrees. Inclinometer and Goniometer gives angular measurement which cannot be used to check the elevation or depression of the scapula whereas palpation meter, tape measures are used to check the linear measurement yet cannot be used to check the elevation and depression of scapula. Lennie's method can be used to check the elevation and depression of scapula but it is limited as it cannot determine whether the scapula is elevated or depressed relative to spinal landmark and needs comparison with other side along with repeated measurements. Protractor method can be used clinically to check the elevation and depression of scapula as it is low cost. It assesses a true measure of vertical distance between landmarks at a right angle to a horizontal plane. ICC to be 0.86 . It cannot be used to measure the diagonal elevation oof scapula [12]. Digital Inclinometer have been used in one of the studies which was validated by Johnson et.al to check the scapular upward rotation [13].

Two studies have used scapular balance angle and Palpation meter to assess the scapular malalignment in patients with stroke. In a literature it is reported that Scapular Balance Angle has been a straightforward and reproducible evaluation for position of scapula as its reliability range from 0.84 to 0.87 [5].

According to studies movement of the upper limb is impaired in $80 \%$ of acute stroke and $40 \%$ in chronic Stroke which limits its functional 
use in Stroke Patients [13]. Very few studies have highlighted the effect of stroke on scapular malalignment and its extent in acute, subacute and chronic Stroke Patients.

Hence the purpose of the study is to investigate the extent of scapular malalignment in patients with Stroke.

\section{METHODOLOGY}

A systematic review was undertaken of all literature concerning the Scapular malalignment in stroke. The keywords like Scapular malalignment, stroke was used to search in PubMed, Google scholar, Science direct, Cochrane library. The electronic search was done by cross checking the references list of all relevant articles. We used the following indexing and text terms to search the data: Scapular malalignment and stroke OR Scapular alignment and stroke.

The Selection Criteria were: Articles were referred for scapular malalignment and stroke. Review contain literature, only studies included within last 10 years. Studies written in English language were included.

Selection criteria: Articles evaluating Scapular malalignment in acute, sub-acute and Chronic stroke, Observational and Case control studies were included. Full text articles from the journal, articles published in English language, Outcome measures that have been considered Valid or Reliable in measuring the Scapular alignment, Articles reviewed only from the online Electronic Database Site.

The Exclusion criteria was articles considering that are Randomized control Trial (RCT), Unpublished articles, outcome measures that are not Valid or Reliable.

Data extraction: The Data Analysis was done through various Electronic Data base searched by EK. The Title and Abstract of all the retrieved results were then screened for eligibility by EK \& SG, the Screening process was aimed at narrowing down the volume of articles by rejecting the studies that are not relevant or appropriate according to previously stated criteria, Full text version of all relevant articles were evaluated by EK and SG.

Data analysis: The selected studies were analysed in terms of specific study design, no. of subjects included, procedure performed, outcome measures used in the study, conclusion, limitations and future scope. Analysis of study design helped to confirm specific type of observational study. Details of participants suggested the stage of stroke whether subacute or chronic. Procedure of each study revealed how the information about Scapular alignment in stroke were collected. Outcome measures description indicated quality of tool along with its psychometric properties. Result of study produced a direction to understand the relationship between the variables that were investigated in each study. Limitations and future scope compiled from each study may trigger the concept of new study among the readers.

Assessment: Articles included in the review were in English language which may have biased some findings. More studies done were on Sub acute and Chronic duration of Stroke.

\section{Scapular malalignment measurement tools:}

For assessing Scapular Malalignment: Upper Limb Motor Assessment Scale, Lennie's test, Protractor, palpation Meter, Scapular Balance Angle, Digital Inclinometer, Acromial distance Test, electromagnetic sensor was commonly used in the selected articles.

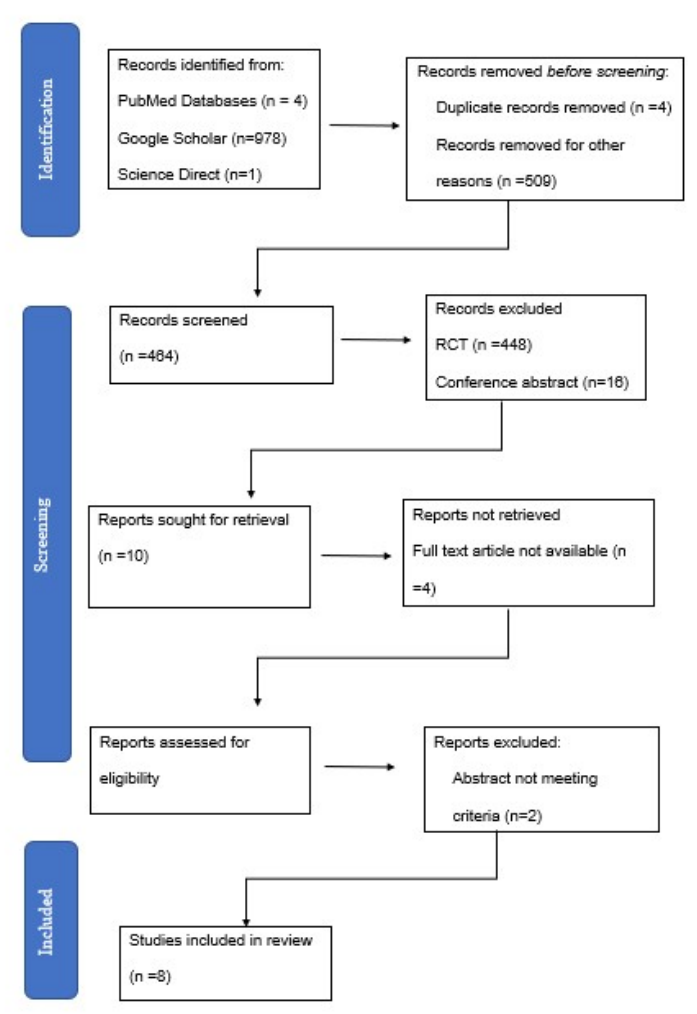


RESULTS

\begin{tabular}{|c|c|c|c|c|}
\hline Study & Design & Subjects and treatment & $\begin{array}{l}\text { Various tools to measure } \\
\text { scapular malalignment }\end{array}$ & Results and Conclusions \\
\hline $\begin{array}{l}\text { Dr. Harsha Zadafiya, Dr. Dhwanit } \\
\text { Shah et. al [14] }\end{array}$ & Cross-sectional Study & $\begin{array}{l}n=72 \text { - both male and female } \\
\geq 3 \text { months } \\
\text { Upper limb mobility and scapular position- } \\
\text { assessed }\end{array}$ & $\begin{array}{l}\text { Protractor, } \\
\text { lennie's test } \\
\text { Upper Limb Motor Assessment } \\
\text { Scale }\end{array}$ & $\begin{array}{l}\text { There is effect of scapular position on } \\
\text { upper limb Mobility among Stroke } \\
\text { Patients. }\end{array}$ \\
\hline $\begin{array}{l}\text { Lama Saad El-Din } \\
\text { Mahmoud,Sobhy Mahmoud Aly } \\
\text { et. al [5] }\end{array}$ & Cross- sectional Study & $\begin{array}{l}\mathrm{n}=60 \text { - onset of } 5 \text { months spasticity were } \\
\text { included. } \\
\text { Divided into two groups: Group A (with } \\
\text { Scapular Dyskinesia) and Group B (without } \\
\text { Scapular Dyskinesia), } \\
\text { The Scapular position- assessed }\end{array}$ & $\begin{array}{l}\text { Palpation Meter, Lateral Scapular } \\
\text { Slide Test, Scapular Balance Angle } \\
\text { and Fugl- Meyer Scale }\end{array}$ & $\begin{array}{l}\text { Scapular dyskinesia had a significant } \\
\text { effect on the scapular balance angle } \\
\text { and upper extremity sensorimotor } \\
\text { function in patients with stoke with } \\
\text { spasticity. }\end{array}$ \\
\hline $\begin{array}{l}\text { Jonjin Ratanapinunchai, Witaya } \\
\text { Mathiyakom et al [15] }\end{array}$ & Cross sectional study & $\begin{array}{l}\mathrm{N}=25 \text { stroke patients- age, gender matched } \\
\text { normal individuals } \\
\text { Scapular upward rotation during rest and } \\
\text { passive movement-checked in } 30^{\circ}, 60^{\circ}, 90^{\circ} \text {, } \\
120^{\circ} \text {, and } 150^{\circ} .\end{array}$ & Digital Inclinometer & $\begin{array}{l}\text { Scapular upward rotation increased as } \\
\text { humeral abduction increased in both } \\
\text { groups. } \\
\text { Scapular upward rotation- } \\
\text { significantly less in hemiplegic group } \\
\text { compared to normal. }\end{array}$ \\
\hline $\begin{array}{l}\text { Esma Nur KOLBAŞI a, Burcu } \\
\text { ERSÖZ HÜSEYiNSiNOĞLUb et.al } \\
\text { [16] }\end{array}$ & Observational Study & $\begin{array}{l}\text { Stroke patients Integrated Evaluation of } \\
\text { Upper Extremity-stroke patients }\end{array}$ & $\begin{array}{l}\text { Dynamometer, } \\
\text { Stop Watch } \\
\text { Goniometer } \\
\text { Fugl-Meyer Assessment Scale }\end{array}$ & $\begin{array}{l}\text { There was more of scapular internal } \\
\text { rotation and anterior tilt in shoulder } \\
\text { elevation and hair combing activities }\end{array}$ \\
\hline Snehal Joshi, Dipti Naik et al [17] & Cross sectional study & $\begin{array}{l}\mathrm{n}=50 \\
\text { duration }>1 \text { month }<2 \text { years } \\
\text { Scapular Positioning was assessed. }\end{array}$ & $\begin{array}{l}\text { Acromial Distance Test, } \\
\text { modified lateral scapular slide } \\
\text { test, } \\
\text { visual observation } \\
\text { goniometer. }\end{array}$ & $\begin{array}{l}\text { Scapular malalignment (scapular } \\
\text { downward tilting and scapular lateral } \\
\text { rotation) does not affect shoulder } \\
\text { Range of Motion }\end{array}$ \\
\hline $\begin{array}{l}\text { Ajit Dabholkar, Devanshi Mehta } \\
\text { et al [11] }\end{array}$ & Cross sectional study & $\begin{array}{l}\mathrm{N}=50 \\
\text { Duration }>3 \text { months } \\
\text { Scapular Position was assessed }\end{array}$ & $\begin{array}{l}\text { SBA (Scapular Balance Angle) } \\
\text { Scapular Dyskinesia Test }\end{array}$ & $\begin{array}{l}\text { Scapular stability is affected as } \\
\text { evaluated by scapular dyskinesia test } \\
\text { and scapular balance angle. }\end{array}$ \\
\hline \multirow[b]{2}{*}{$\begin{array}{l}\text { Johanna V. G. Robertson Nicolas } \\
\text { Roche et al [18] }\end{array}$} & \multirow[b]{2}{*}{ Cross sectional study } & $\mathrm{n}=27$ & MRC scale, & $\begin{array}{l}\text { In left hemisphere damage, scapular } \\
\text { protraction reduced on ipsilateral side } \\
\text { and reduced scapular anterior tilt on } \\
\text { contralateral side. }\end{array}$ \\
\hline & & $\begin{array}{l}\text { two groups } \\
\text { Control=9, stroke }=18 \\
\text { duration }>3 \text { months } \\
\text { Spasticity measured- MAS } \\
\text { Strength, } \\
\text { arm function and Functional Independence- } \\
\text { was assessed }\end{array}$ & Frenchray Scale & $\begin{array}{l}\text { In right hemisphere damage, } \\
\text { glenohumeral elevation greater on } \\
\text { ipsilateral side. }\end{array}$ \\
\hline \multirow{2}{*}{$\begin{array}{l}\text { Derek G. Kamper, , Alicia N. et al } \\
\text { [19] }\end{array}$} & \multirow{2}{*}{ Cross sectional study } & $\mathrm{N}=20$ (16 stroke, 4 control). & $\begin{array}{l}\text { Chedoke-McMaster Stroke Arm } \\
\text { Assessment, } \\
\text { distance, velocity, smoothness, } \\
\text { straightness, }\end{array}$ & $\begin{array}{l}\text { Reaches performed with the } \\
\text { ipsilateral side showed degradation of } \\
\text { movements. } \\
\text { These features correlated strongly } \\
\text { with impairment level, as well as with } \\
\text { each other. }\end{array}$ \\
\hline & & $\begin{array}{l}\text { Subjects perform } 150 \text { reaching movements, } \\
75 \text { - paretic arm and } 75 \text { - contralateral arm. } \\
17 \text {-contralateral arm-functional tasks } \\
\text { Target set- } 75 \text { evenly spaced, ( } 5 \text { latitudinal, } \\
15 \text { longitudinal meridians). }\end{array}$ & $\begin{array}{l}\text { direction of the hand path during } \\
\text { each reach, -an electromagnetic } \\
\text { sensor }\end{array}$ & $\begin{array}{l}\text { Reaching distance showed- strongest } \\
\text { correlations with the other } \\
\text { parameters }\end{array}$ \\
\hline
\end{tabular}

\section{DISCUSSION}

This systematic review predominantly shows the scapular malalignment in patients with Stroke. There is diversity at various levels such as in methodology, population, intervention, outcome measure. Our aim was to report the extent of scapular malalignment in patients with acute, sub-acute and chronic stroke. There are eight studies done including sub-acute and chronic stroke patients. Out of which six included chronic stroke, one acute and two included sub-acute and Chronic

\section{Stroke.}

\section{Effect of scapular malalignment on upper limb} mobility and shoulder range of motion: In a Literature done, it was investigated that upper limb mobility using Motor Assessment Scale had significant correlation with scapular inferior angle and vertical measurements and no significance with superior angle and root of spine. The Mechanism is scapula serves as stable base for arm flexion. Motor control of shoulder is dependent upon the activation of scapular muscles such as trapezius, serratus 
anterior and rhomboids which is altered in stroke [14].

Another study was conducted to check the scapular upward rotation during humeral abduction in stroke as they reported it to be reduced due to disintegration of soft tissues, abnormal muscle tone and weak muscles due to which the scapular motions are avoided while performing passive range of motion and there is no upward rotation of scapula The study reported few future scopes such as longitudinal study in patients with shoulder pain post-stroke is needed to confirm these findings [15].

Another study conducted where they evaluated the whole upper limb and investigated that the scapular muscles undergo in spasticity due to which they pull the scapula into downward rotation. As the muscle groups affected by the spasticity become more dominant leading to scapular depression and retraction occurring due to flexor tone of upper limb. The reduction in scapulohumeral control creates a difficulty during movements of extremities of the impaired side and the risk of hemiplegic shoulder pain may increase and there are chances of subluxation in stroke patients [16].

In another literature it was reported in their studies that the shoulder pain in stroke patients originated from abnormal recruitment of infraspinatus, serratus anterior and inferior trapezius muscles during humeral movement which supported the above literatures [21].

In another study they found that there was lesser posterior scapular tilt observed in stroke patients while elevation phase of shoulder flexion up to $90^{\circ}$ and lateral rotation of scapula while lowering [22].

According to a study, conducted to check on reaching after Stroke and their relation to movement Direction which investigated that there was decrease range of motion was due to restricted scapular motion. The scapula often goes into adduction and rotated downward after stroke as a result of hypertonus or hypotonus muscle [19].

Beer et. al supported the study as he reported that movements performed independently away from the body was problematic. They reported few limitations and future scope of studies. The future scope includes that the rehabilitation for dominant and non-dominant side should be differentiated and the limitation reported was participants included were less severely affected [29].

Study done by Snehal Joshi et al contradicted to it, investigated that scapular position had no significance with shoulder range of motion as they had done it passively. The mechanism behind it there is overactivation of rhomboids muscle as the force coupling between trapezius and serratus anterior gets disturbed after stoke. The disturbance is seen when the movement is done actively. The study also reported few future scopes, correlation of Active Range of Motion with scapular position can be done [17].

Relation of scapular malalignment with duration and hand dominance: According to a study on stroke patient's duration greater than 3 month and they found that there was significant difference found in the scapular position (inferior angle and vertical position) in the duration period between 3 months and 6 months and beyond six months. The mechanism behind it is that scapular spasticity occurs in sub-acute and chronic stage which alters the muscle pull and alters the scapular position.

They also concluded that there was no significance between the dominant and non- dominant affected sides in patient with stroke. This finding was contradicting to an author Harris and Eng et.al who found that patients with chronic stroke with dominant affected hand demonstrated less impairment than nondominant hand affected.

The Study also reported few limitations such as the sampling method was Purposive sampling, Brunnstrom recovery stage and Strength of scapular muscles was not taken into considerations. The study also reported few future scopes of study such as use of Inclinometer and Scapular jig and electromagnetic tracking device. ${ }^{(14)}$

Effect of scapular malalignment on spasticity and upper limb sensorimotor function: In one 
of the studies, it was investigated that Stroke patients had mal-aligned scapula which have decrease capacity to perform isolated arm movements as it had altered scapulohumeral rhythm and altered activation of scapulohumeral muscles. There is absence of retraction due to scapular mala-alignment which leads to altered arm movement or elevation. The literature has been supported by another author Hou et al., which reported that there is scapular malalignment in stroke due to spasticity [20].

The present study had few limitations as Electromyography of scapular muscles, X-ray for $\mathrm{GH}$ joint and scapulothoracic joint was not taken into consideration. Author reported that further studies can be done on by including these assessment methods in the investigation of the effect of scapular dyskinesia on the spine or other neurological conditions [5].

Scapular malalignment and scapular balance angle: Study done on effect of scapular dyskinesia on scapular balance angle and reported that there was significant increase of scapular dyskinesia on scapular balance angle, there is disturbance in in neuromuscular reflex joint, adjustments in the articular mechanoreceptors would bring out sensory inputs that decrease the sensitivity of muscle spindle and hence diminishing proprioception, which show that the role of the proprioceptive system in keeping the shoulder balance and functional activities [5].

Another study supported the study by investigating scapular position was affected in stroke patients when evaluated by scapular balance angle. The mechanism was reported the same [11].

\section{Scapular malalignment and the affected side} of lesion: According to a study, it was investigated scapular protraction is reduced on ipsilateral side and there is reduced scapular anterior tilt on contralateral side. The mechanism stated that there were biomechanical changes.

In right hemisphere damage, glenohumeral elevation greater on ipsilateral side. The alteration in contralateral shoulder motion on the paretic side is classically the direct consequence of the lesion of the crossed descending tracts. The relative preservation of proximal function is also probably due to the preservation of uncrossed corticospinal fibres from the unlesioned hemisphere projecting to axial and girdle muscles [23].

Another literature supported the study as he investigated that there was reduction in protraction on the ipsilateral side during elevation of arm. Another author reported the similar finding [24].

Scapular malalignment in patients with stroke:

Glenohumeral subluxation has been the most common complication seen in patients with stroke. The mechanism was stated by another who reported that scapular muscle weakness, imbalance and fatigue altered the glenohumeral proprioception and the scapular position in patients with stroke.

Another author Edward et al stated that proprioception impairment and injury to joint which leads to altered sensory information by mechanoreceptor can cause scapular malalignment through a direct or indirect trauma [11].

De palma et al noted that rotator cuff would not operate properly for shoulder activities if scapular position is altered [25].

Future studies can be done to investigate the scapular malalignment in stroke along with checking the strength of scapular muscles in Stroke using different instruments like Inclinometer and Scapular jig, and Electromagnetic tracking device for assessment of scapular and humeral motion analysis. Study can be conducted to focus Effect of Scapular strengthening on Upper Limb Mobility on different stages of stroke.

\section{CONCLUSION}

Scapular rotation is significantly more after humeral abduction beyond 90 degrees in patients with stroke. Scapular position (rotation and inferior angle tilting) has an effect on scapular Balance Angle, upper limb Mobility and Sensorimotor Functions of upper limb. The above literature shows that there is more of scapular malalignment observed in sub-acute and chronic patients of stroke as there is increased spasticity in them. However 
more objective methods should be used in future to measure the scapular malalignment.

\section{Conflicts of interest: None \\ REFERENCES}

[1]. Susan B. O’Sullivan et al, Physical Rehabilitation, 2016; 6th (ed):645-719 2.

[2]. Zakaria Y, Rashad U, Mohammed R. Assessment of malalignment of trunk and pelvis in stroke patients. Egypt J Neurol Psychiat Neurosurg. 2010;47(4):599-604.

[3]. AK, Ozukum I, Nilachandra L, Khelendro Th, Nandabir Y, Kunjabasi W. Prevalence of Hemiplegic Shoulder Pain in Poststroke Patients- A Hospital Based Study by Joy International Journal of Physical Medicine and Rehabilitation 2012; Mar;23(1) : 15-9

[4]. Park SE, Kim YR, Kim YY et.al. Immediate effects of scapular stabilizing exercise in chronic stroke patient with winging and elevated scapula: a case study. Journal of physical therapy science. 2018;30(1):190-3.

[5]. Mahmoud LS, Aly SM. The effect of scapular dyskinesia on the scapular balance angle and upper extremity sensorimotor function in stroke patients with spasticity. Bulletin of Faculty of Physical Therapy. 2020 Dec;25(1):1-8.

[6]. Kibler WB,Ludewig PM,McClure PW et al.Clinical implications of scapular dyskinesis in shoulder injury:the 2013 consensus statement from 'scapula summit'.Br J Sports Med 2013;47:877-85

[7]. Barnes CJ, Van Steyn SJ, Fischer RA. The effects of age, sex, and shoulder dominance on range of motion of the shoulder. J Shoulder Elb Surg. 2001; $10: 242-6$

[8]. Kibler WB, Ludewig PM, Mcclure P, Uhl TL, Sciascia A, editors. Scapular Summit 2009, July 16, 2009, Lexington, Kentucky. journal of orthopaedic \& sports physical therapy. 2009 Nov;39(11):A1-3.

[9]. Cailliet R. The shoulder in hemiplegia. 3rd ed. Philadelphia (PA): FA Davis Co; 1980. p. 78-86.

[10]. Chaco J, Wolf E. Subluxation of the glenohumeral joint in hemiplegia. Am J Phys Med. 1971; 50:13943

[11].Dabholkar A, Mehta D, Yardi S, Dabholkar T. Assessment of scapular behaviour in stroke patients. Int J Health Rehabil Sci. 2015;4(2):95-102.

[12]. O'Shea A, Kelly R, Williams S, McKenna L. Reliability and validity of the measurement of scapular position using the protractor method. Physical therapy. 2016 Apr 1;96(4):502-10.

[13]. Scibek JS, Carcia CR. Assessment of scapulohumeral rhythm for scapular plane shoulder elevation using a modified digital inclinometer. World journal of orthopedics. 2012 Jun 18;3(6):87.
[14]. Zadafiya H, Shah D et.al, "An Effect of Scapular Position on Upper Limb Mobility among Stroke Patients in Tertiary Care Hospital: A Cross Sectional Study", International Journal of Science and Research (IJSR); Volume 9 Issue 10, October 2020, 272 $-275$

[15]. Ratanapinunchai J, Mathiyakom W, Sungkarat S. Scapular upward rotation during passive humeral abduction in individuals with hemiplegia poststroke. Annals of rehabilitation medicine. 2019 Apr;43(2):178

[16]. KOLBAPI EN, Hüseyinsinoðlu BE. Integrated Evaluation of Upper Extremity Dysfunction After Stroke: An Overview for Clinical Practice. Türkiye Klinikleri Saðlýk Bilimleri Dergisi. 2019;4(3):390-9.

[17]. Joshi S, Naik D. Effect of scapular malpositioning on shoulder range of motion in stroke patients. International Journal of Current Research and Review. 2016 Jul 15;8(14):17

[18]. Robertson JV, Roche N, Roby-Brami A. Influence of the side of brain damage on postural upper-limb control including the scapula in stroke patients. Experimental brain research. $2012 \mathrm{Apr}$ 1;218(1):141-55.

[19].Kamper DG, McKenna-Cole AN, Kahn LE, Reinkensmeyer DJ. Alterations in reaching after stroke and their relation to movement direction and impairment severity. Archives of physical medicine and rehabilitation. 2002 May 1;83(5):702-7.

[20]. Hou S, Ivanhoe C, Li S. Botulinum toxin injection for spastic scapular dyskinesia after stroke: case series. Medicine (Baltimore). 2015;94.

[21]. De Baets L, Jaspers E, et al. A systematic review of 3D scapular kinematics and muscle activity during elevation in stroke subjects and controls. J Electromyogr Kinesiol. 2013;23(1):3-13

[22]. De Baets L, Van Deun S et al. Three-dimensional kinematics of the scapula and trunk, and associated scapular muscle timing in individuals with stroke. Hum Mov Sci. 2016; 48:82-90

[23]. Meskers CG, Koppe PA, Janssen TW. Kinematic alterations in the ipsilateral shoulder of patients with hemiplegia due to stroke. American journal of physical medicine \& rehabilitation. $2005 \mathrm{Feb}$ 1;84(2):97-105.

[24].Niessen M, Janssen T, Meskers C, Koppe $P$, Konijnenbelt $M$, Veeger $D$. Kinematics of the contralateral and ipsilateral shoulder: a possible relationship with post-stroke shoulder pain. Journal of Rehabilitation Medicine. 2008 Jun 5;40(6):482-6.

[25]. DePalma MJ, Johnson EW. Detecting and treating shoulder impingement syndrome: the role of scapulothoracic dyskinesis. The Physician and sportsmedicine. 2003 Jul 1;31(7):25-32.

How to cite this article: Suvarna S Ganvir, Eram N Kazi. Scapular Malalignment in Patients with Stroke: A Narrative Review. Int J Physiother Res 2021;9(6):4051-4057. DOI: 10.16965/ ijpr.2021.192 